University of Nebraska - Lincoln

DigitalCommons@University of Nebraska - Lincoln

\title{
Aggregated Seed Dispersal by Spider Monkeys Limits Recruitment to Clumped Patterns in Virola calophylla
}

\author{
Sabrina E. Russo \\ University of Nebraska - Lincoln, srusso2@unl.edu \\ Carol K. Augsperger \\ University of Illinois at Urbana-Champaign
}

Follow this and additional works at: https://digitalcommons.unl.edu/bioscifacpub

Part of the Life Sciences Commons

Russo, Sabrina E. and Augsperger, Carol K., "Aggregated Seed Dispersal by Spider Monkeys Limits Recruitment to Clumped Patterns in Virola calophylla" (2004). Faculty Publications in the Biological Sciences. 224.

https://digitalcommons.unl.edu/bioscifacpub/224

This Article is brought to you for free and open access by the Papers in the Biological Sciences at DigitalCommons@University of Nebraska - Lincoln. It has been accepted for inclusion in Faculty Publications in the Biological Sciences by an authorized administrator of DigitalCommons@University of Nebraska - Lincoln. 

mission.

\title{
Aggregated Seed Dispersal by Spider Monkeys Limits Recruitment to Clumped Patterns in Virola calophylla
}

\author{
Sabrina E. Russo ${ }^{1^{*}}$ and Carol K. Augspurger ${ }^{2}$ \\ ${ }^{1}$ Department of Animal Biology, University of Illinois, Urbana, Illinois, U.S.A. \\ ${ }^{2}$ Department of Plant Biology, University of Illinois, Urbana, Illinois, U.S.A.
}

${ }^{*}$ Correspondence and present address: School of Biological Sciences, University of Nebraska-Lincoln, Lincoln, Nebraska, U.S.A.; srusso2@unl.edu

\begin{abstract}
The initial spatial pattern of seed deposition influences plant population and community structure, particularly when that pattern persists through recruitment. In a vertebrate-dispersed rain forest tree, Virola calophylla, we found that spatially aggregated seed deposition strongly influenced the spatial structure of later stages. Seed dispersion was clumped, and seed densities were highest underneath $V$. calophylla females and the sleeping sites of spider monkeys (Ateles paniscus), the key dispersal agent. Although these site types had the lowest per capita seedto-seedling survival, they had the highest seedling/sapling densities. Conversely, seed and seedling/sapling densities were lowest, and seed survival was highest, at sites of diurnal seed dispersal by spider monkeys. Negative density-dependent and positive distance-dependent seed survival thinned seed clumps. Nonetheless, the clumped dispersion at sleeping and parental sites persisted to the seedling/sapling stage because differences in seed deposition were large enough to offset differences in seed survival among these site types.
\end{abstract}

Keywords: Ateles paniscus, Dispersion, Myristicaceae, Neotropical forest, Peru, Recruitment, Seed dispersal, Seed survival, Seedlings, Virola calophylla.

\section{INTRODUCTION}

Seed dispersal results in colonization of potential recruitment sites and establishes the initial template of offspring dispersion. It therefore can strongly influence the spatial distribution of adult plants in a landscape (Howe \& Smallwood 1982; Schupp \& Fuentes 1995). The spatial distribution of individuals, in turn, mediates intra-and interspecific interactions, such as density-dependent mortality and competition, and the balance of these interactions affects species coexistence (Chesson 2000). Thus, understanding the role of seed dispersal in the development of spatial pattern in plant populations is critical to explanations of plant community structure (Levin 1974; Hurtt \& Pacala 1995; Chesson 2000).

The development of spatial pattern in plant populations results from a set of processes governing the pattern of seed deposition and a set of post-dispersal processes that modify that pattern during recruitment (Schupp \& Fuentes 1995; Schupp 1995). First, the spatial extent of seed dispersal restricts the suite of potential sites for recruitment (Howe \& Smallwood 1982). However, there are few descriptions of seed dispersion at spatial scales large enough to encompass the varia- tion in seed density generated by dispersal agents, particularly in forest communities. An increasing number of studies has revealed patterns of seed deposition in forests either by using seed traps and inverse modelling or by developing mechanistic models of the behavior of dispersal agents to simulate seed dispersion (Nathan \& Muller-Landau 2000). These studies suggest that seed deposition is often spatially aggregated, particularly for vertebrate-dispersed tree species (Schupp et al. 2002).

Second, the spatial pattern of seed deposition and the recruitment consequences of that pattern affect the density and dispersion of plants in later life stages (Hubbell 1980; McCanny 1985). One mechanism that has figured prominently in explaining tree dispersion, particularly in tropical forests (Hubbell 1980; Augspurger 1983a; Clark \& Clark 1984; Condit et al. 1992), is survival that depends upon the density of seeds, seedlings, and/ or saplings or their distance from a conspecific adult (Janzen 1970; Connell 1971). Such non-random survival resulting from natural enemies, such as seed predators and seedling pathogens, can thin clumps of seeds and seedlings and produce spatial patterns that differ from what would result simply from random thin- 
ning of the initial seed deposition pattern (Augspurger 1983a). Third, the availability and distribution of sites suitable for establishment, combined with the interactions between a plant's regeneration requirements and its environment and other species, can also influence the spatial pattern of seedling and sapling recruitment (Grubb 1977).

Dispersion of vertebrate-dispersed tree species, then, can be viewed in terms of the balance between dispersal processes that aggregate seeds and post-dispersal processes that alter the initial offspring dispersion pattern through non-random survival (Schupp \& Fuentes 1995; Schupp 1995). However, the recruitment consequences of natural seed deposition patterns remain unquantified for all but a handful of the wide variety of plant-animal disperser systems (e.g. birds, Herrera et al. 1994; Wenny 2000; tapirs, Fragoso 1997; howler monkeys, Julliot 1997; rodents, Forget 1990, 1994, Forget et al. 1999). Despite recent advances (Houle 1992; Herrera et al. 1994; Nathan et al. 2000; Balcomb \& Chapman 2003), the extent to which the spatial patterns of recruitment are determined by the initial seed deposition pattern remains a fundamental unanswered question in plant ecology. Thus, in order to understand the importance of seed dispersal for plant community ecology, we must describe its consequences for later life stages and link patterns of dispersion among multiple life stages (Levine \& Murrell 2003).

The objectives of this study were to investigate the development of spatial structure of a vertebrate-dispersed, neotropical nutmeg tree, Virola calophylla (Myristicaceae), and to determine whether dispersion shifts through time as individuals age. We evaluated how the spatial pattern of recruitment from the seed to the adult stage was modified from the initial template of seed deposition in V. calophylla growing in mature floodplain forest in Amazonian Peru. First, observations documented the spatial pattern of seed deposition. Second, natural and manipulative experiments quantified spatial variation in post-dispersal seed survival to the seedling stage. In particular, the strength of density- and distance-dependent mortality was estimated. Third, patterns of seed deposition and survival were related to densities of $V$. calophylla seedlings and saplings. Finally, the dispersion of juvenile and adult $V$. calophylla individuals was quantified and interpreted in light of the spatial structure of earlier life stages and the strength of density- and distance-dependent survival.

Our results indicate that a clumped pattern of seed deposition was generated by the key dispersal agent, the spider monkey, Ateles paniscus (Platyrrhini). This clumped pattern was largely maintained through recruitment to the sapling stage, despite substantial density- and distance-dependent seed mortality, and was consistent with the clumped dispersion of adults. Thus, spatially aggregated seed dispersal had a strong, persistent effect on the spatial structure of this population of $V$. calophylla.

\section{METHODS}

STUDY SITE

This study was conducted from August 1999 to December 2001 at Cocha Cashu Biological Station (CCBS) in Manú National Park, Perú $(18,812$ km², 115' S, $71^{\circ} 18^{\prime} \mathrm{W}$, elevation c. $400 \mathrm{~m}$ ). The average annual rainfall is c. 2,000 mm, with most precipitation falling between October and April (Terborgh 1983). This study was conducted in c. 300 ha of mature floodplain forest at CCBS. This site has been described in detail in previous publications (Terborgh 1983; Gentry 1990).

\section{DISPERSAL SYSTEM}

Species of Virola have been a model system for studying seed dispersal (e.g. Howe 1981; Howe et al. 1985; Forget \& Milleron 1991). Virola calophylla is a dioecious, shade-tolerant, canopy tree in lowland moist forests of South America (Rodrigues 1980). At CCBS V. calophylla ripens fruit from early to mid-September to December. The fruit of $V$. calophylla is a bivalved, dark green capsule that opens upon ripening to expose a single seed with a bright red, oily aril. Most of the volume of the diaspore is comprised of the seed (length: $17.0 \pm 1.8$ $\mathrm{mm}, n=98$; fresh mass: $1.4 \pm 0.5 \mathrm{~g}, n=108 ; \bar{x} \pm \mathrm{SD}$ ).

At CCBS seeds of $V$. calophylla are dispersed by at least 17 bird species and one primate, the spider monkey, Ateles paniscus (Russo 2003a). Based on 2 years of observations quantifying visitation and seed dispersal rates, spider monkeys dispersed $92 \%$ of dispersed seeds (Russo 2003a). They ingest up to 104 seeds in a visit and defecate them intact after gut passage times that range from c. 2.5 to $18 \mathrm{~h}$ (Milton 1981; S.E. Russo, unpublished data). They are highly frugivorous, forage primarily in the canopy and subcanopy, and have large home ranges (150-230 ha; Symington 1987). Secondary dispersal of $V$. calophylla by rodents (Russo, in press) or dung beetles (Andresen 1994) appears to be minimal at CCBS.

NON-DISPERSED AND NATURALLY AND EXPERIMENTALLY DISPERSED SEEDS

A combination of observational and experimental methods was used to quantify seed deposition patterns and to compare seed survival and germination of non-dispersed seeds (seeds falling below the parent), seeds dispersed by spider monkeys, and experimentally dispersed seeds. To characterize seed production, seed-fall below, and seed dispersal from $V$. calophylla females, 10 female trees bearing fruit in the study area in 2000 were randomly selected. The area of the crown 
projection of each tree was estimated based on the area of an ellipse by measuring four radii of the crown. Beneath each tree, $1-\mathrm{m}^{2}$ fruit traps (3-12 traps per tree) were located randomly using methods described in Russo (2003a). Seed production and dispersal were estimated from fruit- and seed-fall into traps as in Russo (2003a). Next to each trap, a quadrat $(0.5 \times 0.5 \mathrm{~m})$ was delineated on the ground. At each weekly emptying of traps, no more than 10 seeds from the trap were coded individually using colored paint and placed in the quadrat. One seed naturally fallen into the quadrat and not part of the study was removed for each coded seed added, which maintained the natural density of seeds and timing of seed-fall in the quadrat.

Individual spider monkeys that fed in $V$. calophylla were followed to describe movements and behaviors that influence seed dispersal patterns and to characterize and map the locations where spider monkeys defecated $V$. calophylla seeds. When spider monkeys defecated $V$. calophylla seeds, the polygon describing the area receiving freshly defecated seeds was delineated, mapped, and its area estimated using ArcView geographical information systems software. Within this boundary, quadrats $(0.5 \times 0.5 \mathrm{~m})$, were aligned so that each seed was contained within one quadrat, but quadrats could contain more than one seed. All freshly defecated seeds of $V$. calophylla were counted and uniquely coded as above.

Seeds were experimentally dispersed to randomly selected locations in the study area in order to mimic seed dispersal by birds (hereafter, experimental sites). Freshly fallen seeds were collected from underneath multiple fruiting $V$. calophylla trees distant from the study area. The arils were manually removed from the seeds, and damaged seeds were discarded. The intact seeds from the multiple source trees were bulked, and those to be experimentally dispersed were selected at random from the bulked seeds. A random location was selected for placement of paired quadrats $(0.5 \times 0.5 \mathrm{~m})$, each $15-\mathrm{m}$ apart in opposite directions from the random location. Into each quadrat, either six seeds (high density) or one seed (low density) was placed, simulating locations of seeds regurgitated by birds, for a total of 132 quadrats. Seeds were uniquely coded as above. The seeds in quadrats in one pair were all placed on the same day, but pairs were placed at temporally staggered intervals according to the availability of $V$. calophylla seeds, mimicking natural dispersal.

For all quadrats, the date that each seed fell, was naturally dispersed, or was placed into a quadrat ranged from early to late in the $V$. calophylla population's fruiting season (c. 4 months). In each quadrat, the total numbers of $V$. calophylla seeds (including both coded seeds part of the study and uncoded seeds) and of seeds of other species that were $5 \mathrm{~mm}$ or longer were recorded. The distance of each quadrat to the nearest adult female $V$. calophylla tree was calculated based on mapped locations of quadrats and trees.

POST-DISPERSAL SEED SURVIVAL AND SEEDLING ESTABLISHMENT Non-dispersed and naturally and experimentally dispersed seeds were censused every $2 \mathrm{wk}$ for 15 months from September 2000 to December 2001 to estimate seed survival and germination rates. Preliminary studies indicated that $V$. calophylla seeds can germinate and establish seedlings with two leaves in 13 months. Seeds were categorized as (1) intact, but not germinated, (2) removed (seed not found in quadrat), (3) seed present, but preyed upon, and (4) germinated.

SEEDLING, SAPLING, AND ADULT DENSITIES AND DISPERSION Under each female crown and at each site of naturally dispersed seeds, seedlings and saplings $<10 \mathrm{~cm}$ diameter at breast height (d.b.h.) were censused and their heights (or d.b.h. for saplings $>2 \mathrm{~m}$ tall) measured. Density of seedlings and saplings was calculated using the estimated areas of each site (crown projection or dispersal site). To quantify dispersion of seedlings and saplings, 13 parallel belt transects 334-419 $\mathrm{m}$ in length were placed in a stratified random design through a 30-ha plot. Twelve transects were 6-m wide, and one transect was 3-m wide due to proximity of a trail. In each transect, each $V$. calophylla seedling and sapling < $10 \mathrm{~cm}$ d.b.h. was mapped to the nearest $10 \mathrm{~cm}$ and its height or d.b.h. measured. For each individual, its light environment (gap or understorey) was assessed qualitatively. Gaps were considered areas > c. $20 \mathrm{~m}^{2}$ with a canopy height averaging < c. $3 \mathrm{~m}$, as judged by eye. Seedlings and saplings in these transects provided an estimate of seedling and sapling density in random locations. To quantify adult dispersion, all $V$. calophylla trees $\ddagger 10 \mathrm{~cm}$ d.b.h. were mapped in the 30-ha plot.

\section{STATISTICAL ANALYSES}

Statistical analyses focused on seed survival through seedling establishment. It was not possible to analyse separately survival of the seed vs. the seedling because too few seeds survived to germination. Seeds were considered alive if they were intact or germinating (categories 1 and 4 above); otherwise, seeds were considered dead. Because few seeds survived to the end of the study (see Results), probabilities based on asymptotic tests may be biased. We therefore used exact methods in two sets of analyses. First, variation in per capita seed survival among dispersal site types (nondispersed, dispersed and experimental site types) was analyzed using a Fisher's exact test using SAS PROC FREQ (The SAS Institute 2000). Differences in survival probabilities between pairs of site types were estimated using odds ratios, which compare whether the 
probability of an event (in this case survival of a seed) is the same (not significantly different from one) for two groups (Agresti 1990). Odds ratios $>1$ indicate significantly greater survival in the first, relative to the second, group.

The second analysis tested the effects of conspecific seed density and distance from the nearest $V$. calophylla female tree on per capita seed survival. For this set, analysis of deviance using likelihood ratio tests (SAS PROC GENMOD; The SAS Institute 2000) was used to determine the best-fit main-effects model. Odds ratios estimated the strength of the effects of density and distance on survival, corresponding to a unit increase in the predictor variables. We verified probabilities using exact logistic regression by Monte Carlo simulation with 100 replicates, as implemented in LogXact-5 software (LogXact-5 for Windows 2002).

The dispersion of adults in the 30-ha plot and of seedlings and saplings within the 13 randomly placed transects was tested for deviations from complete spatial randomness. For adults, we used the standard $K$ function, which describes the extent to which there is spatial dependence in the arrangement of events. It is defined by the relationship $\lambda K(d)=E$ (number of (events $\leq$ radius $d$ of an arbitrary event)), where $E($ ) denotes the expectation, and $\lambda$ is the intensity, which is estimated by the mean number of events per unit area (Ripley 2003). We used an edge-corrected estimator of $K(d)$ :

$\hat{K}(d)=n^{-2}|A| \sum \sum_{i \neq j} w_{i, j}^{-1} I_{d}\left(d_{i, j}\right)$

where $n$ is the number of points in region $A$ with area $|A|, d_{i j}$ is the distance between the $i$ th and $j$ th points, $w_{i, j}$ is the proportion of the circle with the center at $i$ and passing through $j$, which lies within $A$, and $\operatorname{Id}\left(d_{i, j}\right)$ is an indicator function that is 1 if $d_{i, j}$ is $\leq d$. Estimates of $K(d)$ were adjusted using a variance-stabilizing transformation:

$\hat{L}(d)=\sqrt{\hat{K}(d) / \pi}$

For transects, the $K$-function modified for the one-dimensional case was used. The area $A$ was instead a line $L$, and $\lambda$ in this case was estimated by the mean number of events per unit length. Positions of seedlings and saplings in transects were collapsed to fall along a line, and dispersion of seedlings and saplings combined in each transect was thus analyzed with respect to onedimension using the edge-corrected estimator:

$\widehat{K}(d)=n^{-2}|L| \sum \sum_{i \neq j} c_{i, j} I_{d}\left(d_{i, j}\right)$

where all variables are as above, except $c_{i j}$ is 2 when the distance between the $i$ th and the $j$ th points is great- er than the distance to the nearest edge and 1 otherwise. Confidence envelopes (95\%) for $K(d)$ were constructed by simulating 99 realizations of a completely spatially random process on the area (or line) containing the original point pattern. Observed values exceeding the upper envelope indicate clustering, whereas those falling below the lower envelope indicate regularity (Ripley 2003).

\section{RESULTS}

The 10 focal $V$. calophylla trees produced a total of 35 835 seeds and dispersed an average of $54 \%$ of their seed crops (range 24-77\%). Densities of non-dispersed $V$. calophylla seeds under females were high (Figure 1a, Table 1). Few seeds of species other than $V$. calophylla were found below females, making the total seed density there similar to the seed density of $V$. calophylla (Table 1).
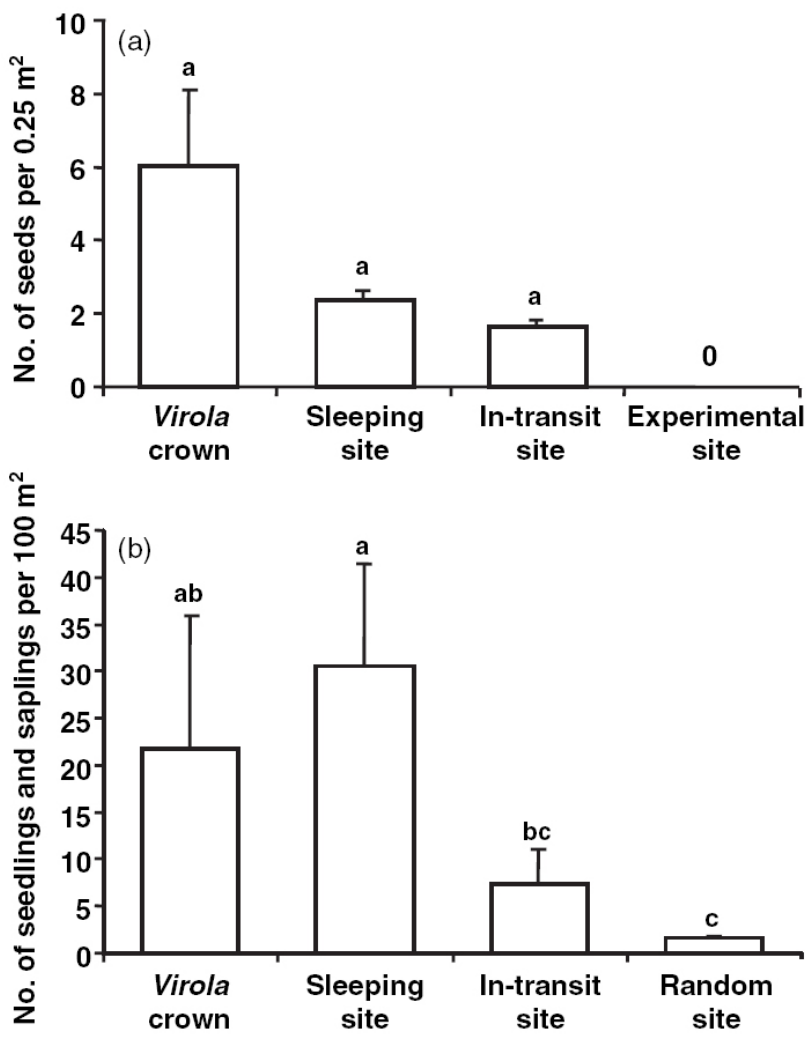

Figure 1. Densities (mean +1 standard error) of seeds (a) and seedlings and saplings (b) of $V$. calophylla under $V$. calophylla crowns $[n=$ 10 in (a), $n=14$ in (b)], under spider monkeys. sleeping $(n=14)$ and in-transit $(n=14)$ sites, and at experimental $[n=132$ in (a)] and randomly located sites [ $n=13$ in (b)]. In-transit sites refer to seeds dispersed diurnally. In (a), density is based onexperimental sites, which were randomly placed. In (b), density in random sites is based on random transects. See text for details. Lower-case letters indicate significant differences based on the Tukey-Kramer method after a significant Kruskal-Wallis test. 
Table 1. Characteristics of dispersal site types of $V$. calophylla in Peru

Characteristic (unit)

Area $\left(\mathrm{m}^{2}\right)$

$V$. calophylla seed density (seeds $0.25 \mathrm{~m}^{-2}$ )

Total seed density (seeds $0.25 \mathrm{~m}^{-2}$ )

Number of species of seeds (species $0.25 \mathrm{~m}^{-2}$ )

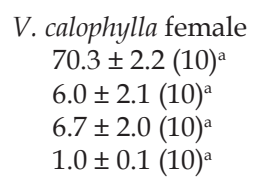

\author{
Sleeping site \\ $89.3 \pm 37.4(13)^{\mathrm{a}}$ \\ $2.4 \pm 0.3(13)^{\mathrm{a}}$ \\ $13.5 \pm 3.3(13)^{\mathrm{a}}$ \\ $3.3 \pm 0.4(13)^{\mathrm{b}}$
}
In-transit site
$18.0 \pm 4.9(14)^{\mathrm{b}}$
$1.6 \pm 0.2(14)^{\mathrm{a}}$
$9.7 \pm 3.7(14)^{\mathrm{a}}$
$2.2 \pm 0.3(14)^{\mathrm{cd}}$

\author{
Experimental site \\ $0^{\mathrm{b}}$ \\ $1.1 \pm 0.4(11)^{\mathrm{b}}$ \\ $1.4 \pm 0.1(11)^{\mathrm{ad}}$
}

Mean \pm 1 standard error and sample size in parentheses. Lower case letters indicate significant differences among site types based on the TukeyKramer method after a significant Kruskal-Wallis test.

Spider monkeys dispersed seeds to two types of sites. First, they defecated seeds during diurnal resting or foraging. Such in-transit sites were infrequently or never re-used, and only one or a few monkeys at a time defecated seeds there. As a result, seeds dispersed in-transit were distributed at widely spaced intervals in the forest. In-transit sites were on average $61 \mathrm{~m}$ from the nearest $V$. calophylla female (range: 26-87 m). Second, spider monkeys defecated seeds at their sleeping sites, where many monkeys congregated at nightfall and in the morning defecated large numbers of seeds. Spider monkeys used at least 14 sleeping sites in the study area in 2000 and re-used $67 \%$ of these at least once during the study. Sleeping sites were on average $48 \mathrm{~m}$ from the nearest $V$. calophylla female (range: 12-86 m).

In-transit sites were consistent with scatter dispersal (sensu Howe 1989) in that these sites were small in area and had low seed density (Table 1). In contrast, seed dispersal to sleeping sites was consistent with a clumped pattern of dispersal (sensu Howe 1989) because sleeping sites were larger in area and tended to accumulate higher densities of seeds, relative to intransit sites (Table 1). The mean area under a sleeping site did not differ significantly from that under a $V$. calophylla crown, but both were significantly larger than an in-transit site (Table 1). Densities of $V$. calophylla seeds under female crowns and under sleeping sites tended to be greater than at in-transit sites (Figure 1a, Table 1). The seed densities in Table 1 are measured at one time point, and so did not account for the repeated seed-deposition within and among years that occurred at most sleeping sites.

The number of seed species under sleeping sites was significantly greater than at in-transit sites, both of which were significantly greater than underneath female crowns (Table 1). Consequently, although densities of $V$. calophylla seeds under female crowns tended to be greater than under sleeping sites, total seed density of all species tended to be higher under sleeping sites and in-transit sites than under female crowns (Table 1). Experimental sites had the lowest seed densities (Table 1).

A total of $99 \%$ ( $n=1,557$ of 1,574 seeds) of naturally and experimentally dispersed seeds failed to es- tablish seedlings by the end of 13-15 months; $60 \%$ had been preyed upon after only 16 days. Per capita seed survival differed among the four dispersal site types at the end of the study (numbers of surviving seeds: $V$. calophylla females, $n=1$; sleeping sites, $n=$ 2; in-transit sites, $n=4$; experimental sites, $n=10$; $P$ $<0.0001$, Fisher's exact test). Seeds under $V$. calophylla females ( $n=639$ seeds) and under sleeping sites $(n$ $=434$ seeds) had equally poor odds of surviving (Table 2). Seeds at in-transit ( $n=77$ seeds) and experimental ( $n=425$ seeds) sites did not differ significantly in survival (Table 2). Their odds of surviving were significantly higher than either seeds under V. calophylla females (Table 2) or under sleeping sites (Table 2 ). The density of $V$. calophylla seeds in a quadrat and the distance from the nearest female $V$. calophylla tree both significantly affected per capita seed survival $\left(\chi^{2}\right.$ $=12.07, \mathrm{P}=0.0005$ for density; $\chi^{2}=8.36, P=0.0038$ for distance; logistic regression). Seeds in quadrats with lower conspecific seed density and further away from an adult female conspecific had a higher probability of surviving (odds ratios: $0.77,95 \% \mathrm{CI}=0.60-0.93, P=$ 0.01 for density; $1.01,95 \% \mathrm{CI}=1.01-1.02, P=0.01$ for distance; logistic regression).

The density of seedlings and saplings of $V$. calophylla was greatest under spider monkey sleeping sites and female trees, relative to that at in-transit sites in the random transects (Figure 1b). Heights of seedlings and saplings did not differ among the four site types (analysis of variance, $P>0.05$ ). Among sites, the mean density of $V$. calophylla seeds was significantly correlated with the density of seedlings and saplings (Spearman rank correlation, $r=0.45, P=0.009)$. Transects differed in the spatial scale of variation in dispersion of seedlings and saplings (Figure 2a-m). However, overall, seedlings and saplings were significantly clumped at spatial scales $<150 \mathrm{~m}$, similar to the dimensions of sleeping sites and $V$. calophylla crowns (10 of 13 transects; Figure 2a-m), and had random or significantly regular dispersion at larger spatial scales (10 of 13 transects; Figure 2a-m). Therefore, seedlings and saplings occurred in clumps similar in size to sleeping sites and $V$. calophylla crowns, and these clumps were randomly or regularly distributed throughout the forest. Clumps of seedlings and saplings were not con- 
Table 2. Odds ratio estimates, 95\% confidence intervals (95\% CI), and probabilities estimated using Fisher's exact test for pairwise comparisons of seed survival at dispersal site types

Site type comparison

In-transit site vs. sleeping site

Experimental site vs. sleeping site

In-transit site vs. $V$. calophylla female

Experimental site vs. V. calophylla female

In-transit site vs. experimental site

$V$. calophylla female vs. sleeping site

Odds ratio
23.8
10.5
17.4
7.7
2.3
1.4

Odds ratios $>1$ indicate higher survival in the first site of the pair. When the $95 \%$ CIs of the odds ratio include the value 1 , the probability of seed survival does not differ significantly between the two site types.

$\begin{array}{cc}95 \% \text { CI } & P \\ 2.6-1173.7 & 0.002 \\ 1.5-454.9 & 0.005 \\ 2.4-194.1 & 0.002 \\ 1.6-72.1 & 0.005 \\ 0.5-8.1 & 0.247 \\ 0.07-80.51 & 0.999\end{array}$

0.005

0.005

0.247 sistently associated with gaps. The density of $V$. calophylla adults in the study plot was 2.9 trees ha ${ }^{-1}$. Adults were significantly clumped at spatial scales of 30-231 m (Figure 2n).

\section{DISCUSSION}

The initially clumped seed deposition pattern was largely maintained through recruitment to the sapling stage in $V$. calophylla. The density of seedlings and saplings was highest where seed-fall was greatest, that is, under $V$. calophylla females and spider monkeys. sleeping sites, as would be predicted by Hubbell $(1980)$. The snapshot of seed densities at these site types, however, does not account for the repeated seed-deposition within and among years at sleeping sites and V. calophylla females. Re-use of sleeping sites has been observed in other Ateline monkeys (e.g. Ateles geoffroyi, Chapman 1989; Alouatta seniculus, Julliot 1997). Conversely, spider monkeys' in-transit sites were rarely reused. Thus, when an entire fruiting season and a timescale relevant for sapling recruitment are considered, seed deposition would be far greater at sleeping sites and $V$. calophylla females than at in-transit sites. This would result in strongly clumped seed dispersion, as shown in a model of this seed dispersal system (Russo $2003 b$ ). Unaccounted-for, repeated seed deposition at sleeping sites also may explain the trend of higher seedling/sapling densities there compared with $\mathrm{V}$. calophylla females, even though the observed seed densities under females tended to be higher than under sleeping sites.

On a per capita basis, seed survival was highest at intransit and experimental seed dispersal sites, yet these sites had the lowest density of seedlings because few seeds fell there. In contrast, the numerical advantage of high seed deposition at sleeping sites and beneath $V$. calophylla females was drastically reduced by the seedling/sapling stage due to the low seed survival there, relative to in-transit and experimental seed dispersal sites. Nonetheless, the clumped offspring dispersion at sleeping and parental sites persisted to the seedling/sapling stage simply because the differences in per capita survival among these dispersal site types were not large enough to offset differences in seed deposition. An independent test corroborated the observation that the clumped dispersion at the seed stage persisted through the sapling stage. In the randomly placed transects, seedlings and saplings were clumped at spatial scales similar to the sizes of sleeping sites and $V$. calophylla crowns.

Furthermore, the clumped recruitment pattern of seedlings and saplings at sleeping and parental sites arose despite the dependence of per capita seed survival on the density of $V$. calophylla seeds and their distance from the nearest female $V$. calophylla tree. Therefore, although Janzen-Connell mechanisms caused substantial non-random thinning of seed aggregations, these mechanisms were apparently not strong enough to eliminate the clumped offspring dispersion established by seed dispersal. Thus, spatially aggregated seed dispersal appears to play a significant role in the spatial structuring of this tropical tree population.

\section{SPATIAL PATTERN OF SEED DEPOSITION}

Seed deposition of $V$. calophylla is characterized by a combination of scatter and clump dispersal patterns (sensu Howe 1989). This combination results from the behaviors and movements of its key dispersal agent, the spider monkey, and appears to be largely unmodified by secondary dispersal by vertebrates (Russo, in press) or dung beetles (Andresen 1994) at CCBS. The effect of combined scatter- and clump-dispersal, along with aggregations of non-dispersed seeds, is to produce substantial spatial variation in seed density at the scale of a forest stand. Theory has shown that, when survival is density-dependent, spatial variation in density among subpopulations can modulate the magnitude of population fluctuations at larger scales (Chesson 1998). Thus, seed dispersal by spider monkeys may influence the stability of $V$. calophylla seedling populations. 

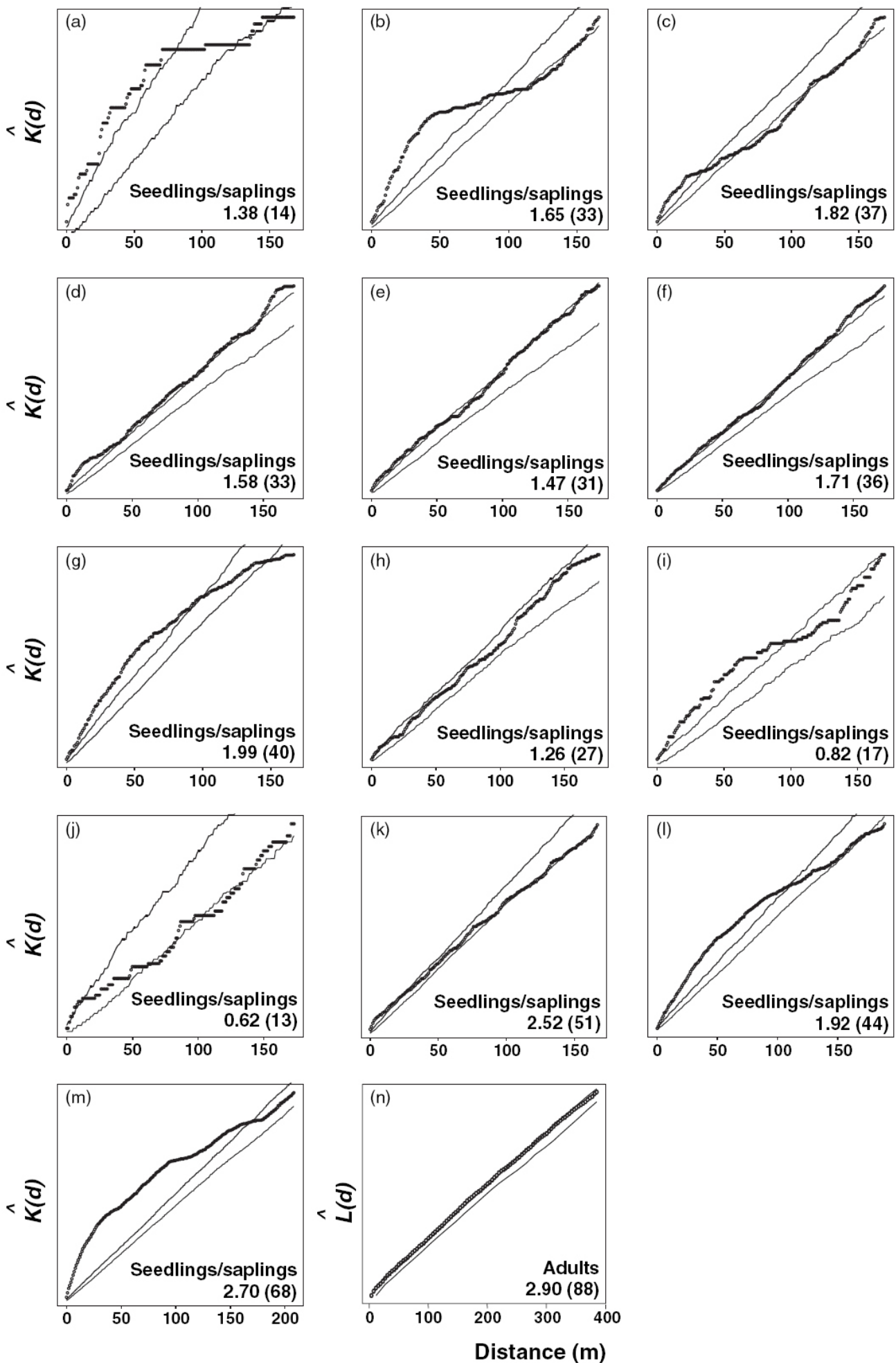

Figure 2. Spatial patterns of $V$. calophylla seedlings and saplings combined (a-m) and adult trees (n) analyzed by plotting the K-statistic vs. distance. Dots are the observed values, and lines are $95 \%$ confidence intervals (CI) for complete spatial randomness based on simulations of a random point pattern. Observed values that exceed the upper CI indicate significant clumping, whereas those that are less than the lower $\mathrm{CI}$ indicate significant regularity. (a)-(m) Seedlings and saplings in 13 parallel transects randomly placed through the study plot; (n) adult trees $\geq 10$ $\mathrm{cm}$ diameter in the study plot. The K-statistic for transects was estimated based on a one-dimensional (linear) model as described in the text. The overall density is in the lower right corner as the number of individuals $100 \mathrm{~m}^{-2}$ for (a)-(m) and per ha for (n); sample sizes (numbers of individuals) are in parentheses. The scales of the ordinal axes are not the same for all graphs and are not displayed because only the comparisons of observed values with the CIs are relevant. 
Recruitment consequences of the spatial pattern of seed deposition

Survival of seeds was low and similar to estimates in other large-seeded tropical trees (Howe et al. 1985; Augspurger \& Kitajima 1992; Terborgh \& Wright 1994; Wenny 2000). To the extent that experimental sites simulated avian dispersal, $V$. calophylla seeds dispersed by birds would have greater odds of surviving, relative to seeds at spider monkeys. sleeping sites or $V$. calophylla females. We found significant differences among dispersal site types in per capita seed survival, but as in other studies (e.g. Herrera et al. 1994; Balcomb \& Chapman 2003), there was considerable variability. Although such variability reduces the predictability of the consequences of seed deposition patterns, even small, consistent differences among site types, accumulated over the large numbers of seeds deposited during time-scales relevant for sapling recruitment, can shape recruitment patterns, as we observed here.

The local density of $V$. calophylla seeds affected their survival. Based on our odds ratio estimate, an increase in density from one to five seeds would result in a 2.8 times worse odds of surviving. Survival of $V$. calophylla seeds was also positively distance-dependent. In contrast, a study in Panama found no effect of distance for the survival of ungerminated $V$. nobilis seeds, although young seedlings experienced severe distancedependent mortality (Howe et al. 1985). By 12 weeks, $V$. nobilis seedlings that were $45 \mathrm{~m}$ from the parent had a 44-times increase in the odds of survival (Howe et al. 1985). The distance effect observed for survival of $V$. calophylla seeds was weaker, but would still result in an estimated 1.6-times greater odds of surviving for seeds $45 \mathrm{~m}$ from the nearest $V$. calophylla female.

Seeds at sleeping sites had similar survival to those underneath $V$. calophylla females, although they were distant from $V$. calophylla females, indicating that density- and distance-dependence can act independently on seed survival in this system. Furthermore, other factors beyond their high $V$. calophylla seed density likely contributed to low survival at sleeping sites. Because of their large size, sleeping sites have more seeds of $V$. calophylla, as well as of other species, than in-transit sites. Consequently, they present a large and diverse food resource that may be more attractive to seed predators than are in-transit sites. Although the density-dependence originally proposed by Janzen (1970) and Connell (1971) involves only conspecific density, the low survival of $V$. calophylla seeds at sleeping sites should be viewed in the context of the speciesrich community of seeds there, not just seeds of $V$. calophylla. The benefit of escaping predation at the parent by being dispersed away from it (Howe \& Smallwood 1982 ) is therefore reduced for seeds dispersed to sleeping sites. Furthermore, the differences among dispersal site types in seed survival suggest that seed predators may also respond to large-scale variation in resourceavailability in addition to local, within-site variation in seed density, as suggested by Schupp (1992). Sleeping sites and $V$. calophylla females are likely higher quality resource patches because they are larger in area, have higher seed densities, and are re-used more frequently than either in-transit or experimental sites.

Spiny rats (Proechimys spp. Rodentia, Echimyiidae) and Scolytid beetles in the genera Coccotrypes and Spermophthorus appear to be some of the most important predators of $V$. calophylla seeds at CCBS (Russo, in press), and are thus likely to be agents of the densityand distance-dependent seed survival observed. Other terrestrial vertebrates, such as agoutis and acouchies, are also likely to prey upon $V$. calophylla, as observed for congeners elsewhere (Forget \& Milleron 1991; Asquith et al. 1997).

SEEDLING, SAPLING, AND ADULT DENSITY AND DISPERSION Seedlings and saplings were clumped at spatial scales similar to the areas of sleeping sites and $V$. calophylla crowns. These clumps likely result from the aggregated pattern of seed deposition at these dispersal site types. Similar patterns have been observed in other dispersal systems (Schupp et al. 2002). In a Ugandan forest, the greatest percentage of seedlings of a primate dispersed tree were predicted to come from seeds dispersed by being defecated in clumps, despite their low per capita survival, simply because greater numbers of seeds were defecated in clumps compared with seeds dispersed by being spit singly (Balcomb \& Chapman 2003). Clumps of seedlings underneath sleeping sites of Alouatta seniculus not only occur at higher density, but also have higher species richness than control areas (Julliot 1997). Similarly, deposition of seeds of the palm, Maximiliana maripa (Palmae), by tapirs at their latrines generated aggregations of seedlings and saplings that were linked to the high-density clumps of adults observed (Fragoso 1997).

The biotic and abiotic factors affecting survival and growth of $V$. calophylla after the seedling stage are not known. Density- and distance-dependent mortality in later life stages as a result of herbivores and pathogens may further thin seedling and sapling clumps (Augspurger 1983b; Clark \& Clark 1984; Gilbert et al. 1994) and likely contribute to the reduced intensity of clumping of $V$. calophylla adults, relative to seedlings and saplings. In addition to seed dispersal, non-random dispersion can also result from species-specific regeneration requirements or interspecific interactions (Grubb 1977). If such effects are strong, they can result in the de-coupling of seed deposition and recruitment patterns (Herrera et al. 1994; Rey \& Alcantara 2000). However, we found no evidence of such de-coupling. 
The mechanisms of density- and distance-dependent mortality of seeds, seedlings, and saplings can have important consequences in many forests (Clark \& Clark 1984; Gilbert et al. 1994; Harms et al. 2000; Hille Ris Lambers et al. 2002), and strong evidence was found for these mechanisms for $V$. calophylla. Nonetheless, clumped distributions of $V$. calophylla persisted at all life stages investigated. Thus, the spatial structure of this $V$. calophylla population is substantially influenced by spatially aggregated seed dispersal, although density- and distance-dependent mortality play important roles in thinning clumped distributions of offspring as they age.

\section{ACKNOWLEDGEMENTS}

Financial support was provided by a National Science Foundation Predoctoral Fellowship, Francis M. and Harlie M. Clark Research and Dissertation Travel Grants from the University of Illinois, and the Organization for Tropical Studies. The Instituto Nacionál de Recursos Naturales in Peru graciously granted permission to conduct this research. George O. Batzli, Jeffrey D. Brawn, Christina Caruso, Gregory Gilbert, Stephen Portnoy, and Scott K. Robinson provided insightful comments on earlier versions of this manuscript. Mercedes Foster and John Teborgh contributed to the development of this project. We thank Julian Avery, Silvia Castro Delgado, Beatriz Fuente Alba Durand, Julian Huarancasi, Brian Lenz, Luis Alza Leon, Thomas J. Near, Timothy Paine, and Jill Rowland for tireless assistance in the field. Susanne Aref, Jeff Douglas, and Heather Lynch provided valuable help with statistical analyses.

\section{REFERENCES}

Agresti, A. (1990). Categorical Data Analysis. John Wiley and Sons, New York.

Andresen, E. (1994). Frugivory and seed dispersal by spider monkeys (Ateles paniscus) and howler monkeys (Alouatta seniculus) and the fate of dispersed seeds at Manu National Park, Peru. MSc Thesis, Duke University, Durham, N.C.

Asquith, N.M., Wright, S.J. \& Clauss, M.J. (1997). Does mammal community composition control recruitment in neotropical forests? Evidence from Panama. Ecology, 78, 941-946.

Augspurger, C.K. (1983a). Offspring recruitment around tropical trees: changes in cohort distance with time. Oikos, 40, 189-196.

Augspurger, C.K. (1983b). Seed dispersal of the tropical tree, Platypodium elegans, and the escape of its seedlings from fungal pathogens. J. Ecol., 71, 759-771.

Augspurger, C.K. \& Kitajima, K. (1992). Experimental studies of seedling recruitment from contrasting seed distributions. Ecology, 73, 1270-1284.

Balcomb, S.R. \& Chapman, C.A. (2003). Bridging the gap: influence of seed deposition on seedling recruitment in a primate-tree interaction. Ecol. Monogr., 73, 625-642.

Chapman, C.A. (1989). Spider monkey sleeping sites: use and availability. Am. J. Primatol., 18, 53-60.

Chesson, P. (1998). Spatial scales in the study of reef fishes: a theoretical perspective. Aust. J. Ecol., 23, 209-215.

Chesson, P. (2000). General theory of competitivecoexistencein spatially-varying environments. Theor. Pop. Biol., 58, 211-237.
Clark, D.A. \& Clark, D.B. (1984). Spacing dynamics of a tropical rain forest tree: evaluation of the Janzen-Connell model. Am. Nat., 124, 769-788.

Condit, R., Hubbell, S.P. \& Foster, R.B. (1992). Recruitment near conspecific adults and the maintenance of tree and shrub diversity in a neotropical forest. Am. Nat., 140, 261286.

Connell, J.H. (1971). On the role of natural enemies in preventing competitive exclusion in some marine animals and in rain forest trees. In: Editors, P.J. den Boer \& G.R. Gradwell, Proceedings of the Advanced Study Institute on Dynamics of Numbers in Populations. Center for Agricultural Publishing and Documentation, Wageningen, Osterbeek, Netherlands, pp. 298-312.

Forget, P.M. (1990). Seed-dispersal of Vouacapoua americana (Caesalpiniaceae) by caviomorph rodents in French Guiana. J. Trop. Ecol., 6, 459-468.

Forget, P.M. (1994). Recruitment pattern of Vouacapoua americana (Caesalpinaceae), a rodent-dispersed tree species in French Guiana. Biotropica, 26, 408-419.

Forget, P.M. \& Milleron, T. (1991). Evidence for secondary seed dispersal by rodents in Panama. Oecologia, 87, 596-599.

Forget, P.-M., Mercier, F. \& Collinet, F. (1999). Spatial patterns of two rodent-dispersed rain forest trees Carapa procera (Meliaceae) and Vouacapoua americana (Caesalpiniaceae) at Paracou, French Guiana. J. Trop. Ecol., 15, 301-313.

Fragoso, J.M.V. (1997). Tapir-generated seed shadows: scaledependent patchiness in the Amazon rain forest. J. Ecol., 85, 519-529.

Gentry, A.H. (1990). Four Neotropical Forests. Yale University Press, New Haven, Conn.

Gilbert, G.S., Hubbell, S.P. \& Foster, R.B. (1994). Density and distance-to adult effects of a canker disease of trees in a moist tropical forest. Oecologia, 98, 100-108.

Grubb, P.J. (1977). The maintenance of species-richness in plant communities: the importance of the regeneration niche. Biol. Rev., 52, 107-145.

Harms, K.E., Wright, S.J., Calderon, O., Hernandez, A. \& Herre, E.A. (2000). Pervasive density-dependent recruitment enhances seedling diversity in a tropical forest. $\mathrm{Na}$ ture, 404, 493-495.

Herrera, C.M., Jordano, P., Lopez-Soria, L. \& Amat, J.A. (1994). Recruitment of a mast-fruiting, bird-dispersed tree: bridging frugivore activity and seedling establishment. Ecol. Monogr., 64, 315-344.

Hille Ris Lambers, J., Clark, J.S. \& Beckage, B. (2002). Density-dependent mortality and the latitudinal gradient in species diversity. Nature, 417, 732-735.

Houle, G. (1992). Spatial relationship between seed and seedling abundance and mortality in a deciduous forest of northeastern North America. J. Ecol., 80, 99-108.

Howe, H.F. (1981). Dispersal of a neotropical nutmeg (Virola sebifera) by birds. Auk, 98, 88-98.

Howe, H.F. (1989). Scatter- and clump-dispersal and seedling demography: hypothesis and implications. Oecologia, $79,417-426$.

Howe, H.F. \& Smallwood, J. (1982). Ecology of seed dispersal. Ann. Rev. Ecol. Syst., 13, 201-228.

Howe, H.F., Schupp, E.W. \& Westley, L.C. (1985). Early consequences of seed dispersal for a neotropical tree (Virola surinamensis). Ecology, 66, 781-791. 
Hubbell, S.P. (1980). Seed predation and the coexistence of tree species in tropical forests. Oikos, 35, 214-229.

Hurtt, G.C. \& Pacala, S.W. (1995). The consequences of recruitment limitation: reconciling chance, history, and competitive differences between plants. J. Theor. Biol., 176, 1-12.

Janzen, D.H. (1970). Herbivores and the number of tree species in tropical forests. Am. Nat., 104, 501-528.

Julliot, C. (1997). Impact of seed dispersal by red howler monkeys Alouatta seniculus on the seedling population in the understorey of tropical rain forest. J. Ecol., 85, 431-440.

Levin, S.A. (1974). Dispersion and population interactions. Am. Nat., 108, 207-228.

Levine, J.M. \& Murrell, D.J. (2003). The community-level consequences of seed dispersal patterns. Ann. Rev. Ecol. Evol. Syst., 34, 549-574.

LogXact-5 for Windows (2002). Logistic Regression Software Featuring Exact Methods. Cytel Software Corporation, Cambridge, Mass.

McCanny, S.J. (1985). Alternatives in parent-offspring relationships in plants. Oikos, 45, 148-149.

Milton, K. (1981). Food choice and digestive strategies of two sympatric primate species. Am. Nat., 117, 496-505.

Nathan, R. \& Muller-Landau, H.C. (2000). Spatial patterns of seed dispersal, their determinants and consequences for recruitment. TREE, 15, 278-285.

Nathan, R., Safriel, U.N., Noy-Meir, I. \&Schiller, G. (2000).Spatiotemporal variation in seed dispersal and recruitment near and far from Pinus halepensis trees. Ecology, 81, 2,156-2,169.

Rey, P.J. \& Alcantara, J.M. (2000). Recruitment dynamics of a fleshy-fruited plant (Olea europaea): connecting patterns of seed dispersal to seedling establishment. J. Ecol., 88, 622-633.

Ripley, B.D. (2003). Statistical Analysis of Spatial Point Patterns. Oxford University Press, Oxford.

Rodrigues,W.A.(1980). Revisaotaxonomicadasespecies de $\mathrm{Vi}$ rolaAublet(Myristicaceae)doBrasil.ActaAmazonica,10,1-127.

Russo, S.E. (2003a). Responses of dispersal agents to tree and fruit traits in Virola calophylla (Myristicaceae): implications for selection. Oecologia, 136, 80-87.
Russo, S.E. (2003b). Linking Spatial Patterns of Seed Dispersal and Plant Recruitment in a Neotropical Tree, Virola calophylla (Myristicaceae). Ph.D. thesis, University of Illinois, Urbana, Ill.

Russo, S.E. (in press). Linking seed fate to dispersal patterns: identifying factors affecting predation and scatter-hoarding of seeds of Virola calophylla in Peru. J. Trop. Ecol.

Schupp, E.W. (1992). The Janzen-Connell model for tropical tree diversity: population implications and the importance of spatial scale. Am. Nat., 140, 526-530.

Schupp, E.W. (1995). Seed-seedling conflicts, habitat choice, and patterns of plant recruitment. Am. J. Bot., 82, 399-409.

Schupp, E.W. \& Fuentes, M. (1995). Spatial patterns of seed dispersal and the unification of plant population ecology. Ecoscience, 2, 267-275.

Schupp, E.W., Milleron, T. \& Russo, S.E. (2002). Dissemination limitation and the origin and maintenance of speciesrich tropical forests. In: Editors, D.J. Levey, W.R. Silva \& M. Galetti, Seed Dispersal and Frugivory: Ecology, Evolution, and Conservation. CABI Publishing, New York, pp. 19-34.

Symington, M.M. (1987). Demography, ranging patterns, and activity budgets of black spider monkeys (Ateles paniscus chamek) in the Manú National Park, Peru. Am. J. Primatol., 15, 45-67.

Terborgh, J. (1983). Five New World Primates. Princeton University Press, Princeton, N.J.

Terborgh, J. \& Wright, S.J. (1994). Effects of mammalian herbivores on plant recruitment in two neotropical forests. Ecology, 75, 1829-1833.

The SAS Institute (2000). The SAS System Release 8.1. The SAS Institute, Inc., Cary, N.C.

Wenny, D.G. (2000). Seed dispersal, seed predation, and seedling recruitment of a neotropical montane tree. Ecol. Monogr., 70, 331-351.

Editor of the published version, Marcel Rejmanek. Manuscript received April 28, 2004; first decision made June 5, 2004; manuscript accepted July 26, 2004. 